\title{
The effect of body position on compartmental intra-abdominal pressure following liver transplantation
}

\author{
Adrian B Cresswell, Wayel Jassem, Parthi Srinivasan, Andreas A Prachalias, Elizabeth Sizer, William Burnal, \\ Georg Auzinger, Paolo Muiesan, Nigel D Heaton, Matthew J Bowles, Julia A Wendon*
}

\begin{abstract}
Background: Current assumptions rely on intra-abdominal pressure (IAP) being uniform across the abdominal cavity. The abdominal contents are, however, a heterogeneous mix of solid, liquid and gas, and pressure transmission may not be uniform. The current study examines the upper and lower IAP following liver transplantation.
\end{abstract}

Methods: IAP was measured directly via intra-peritoneal catheters placed at the liver and outside the bladder. Compartmental pressure data were recorded at 10-min intervals for up to $72 \mathrm{~h}$ following surgery, and the effect of intermittent posture change on compartmental pressures was also studied. Pelvic intra-peritoneal pressure was compared to intra-bladder pressure measured via a FoleyManometer.

Results: A significant variation in upper and lower IAP of 18\% was observed with a range of differences of 0 to 16 $\mathrm{mmHg}$. A sustained difference in inter-compartmental pressure of $4 \mathrm{mmHg}$ or more was present for $23 \%$ of the study time. Head-up positioning at $30^{\circ}$ provided a protective effect on upper intra-abdominal pressure, resulting in a significant reduction in all patients. There was excellent agreement between intra-bladder and pelvic pressure.

Conclusions: A clinically significant variation in inter-compartmental pressure exists following liver transplantation, which can be manipulated by changes to body position. The existence of regional pressure differences suggests that IAP monitoring at the bladder alone may under-diagnose intra-abdominal hypertension and abdominal compartment syndrome in these patients. The upper and lower abdomen may need to be considered as separate entities in certain conditions.

\section{Introduction}

Interest in the measurement of intra-abdominal pressure (IAP) has grown steadily over the last decade and has been shown to be a significant problem within the general intensive care unit (ICU) population [1,2], with the deleterious effects of elevated IAP having been well described in numerous clinical studies and reviews [3-15]. The culmination of the recent increase in interest in this condition has been the creation, by an international panel of experts (The World Society on Abdominal Compartment Syndrome, WSACS, http://

\footnotetext{
* Correspondence: julia.wendon@kcl.ac.uk Liver Transplant Surgical Service and Liver Intensive Care Unit, Kings College London, Institute of Liver Studies, King's College Hospital, Denmark Hill, SE5 9RS, London, UK
}

www.wsacs.org), of a consensus document for definitions [16] and suggested management guidelines [17].

Underpinning these recommendations, however, is a requirement for accurate and reproducible measurement of IAP with several studies having shown that there is no role for clinical estimation of IAP, either by palpation or measurement of abdominal perimeter [18-20].

Numerous techniques for the measurement of IAP by both direct and indirect methods have been described, with indirect approaches utilizing measurement of the pressure concealed within a hollow intra-abdominal viscus most usually the urinary bladder (intra-bladder pressure, IBP) [21] or stomach (intra-gastric pressure, IGP) [22]. Direct methods for measuring IAP have been employed exclusively in the experimental setting whereby the IAP is 
transduced directly from the peritoneal cavity via a catheter containing a continuous column of fluid [23], a balloon-tipped catheter [24] or via a laparoscopic gas insufflation system [25]. The application of such techniques is clearly limited by their invasiveness, and no advantage over indirect measurements has been demonstrated in terms of accuracy.

On the face of the available data, therefore, a non-invasive technique such as the IBP or IGP method would seem more attractive for routine clinical use. This, however, relies on two unproven assumptions regarding the transmission of pressure throughout the abdomen. The first assumption is that the bladder wall will act as a passive diaphragm for the transmission of pressure, and the second is that IAP is transmitted uniformly throughout the abdominal cavity such that the measured pressure at any one position will be reflected elsewhere in the cavity.

The second assumption relies on the contents of the intra-abdominal cavity, transmitting pressure as a single compartment, which, given the heterogeneous mix of contents, may not hold true. Such a regional variation in postoperative patients would have important implications both for the post-operative screening of IAP following surgery and for the potential of a localised effect on the regional organ systems that may not be manifested by the measurement of the relatively remote IBP. This concept would be synonymous with the poly-compartment syndrome which has previously been suggested to affect the head, thorax, abdomen [26] and extremities.

It has been shown that IAP can be influenced by body position with an increase in bladder pressure of up to 7.5 $\mathrm{mmHg}$ with a $45^{\circ}$ positioning angle [27]. However, the effect of body position on the individual intra-abdominal compartment has not previously been described.

Liver transplantation was chosen for the study as a major intervention that has been shown to be associated with a significant incidence of intra-abdominal hypertension (IAH) in both our own unpublished data and in studies from other institutions [28]. The surgical procedure itself is relatively standardised and confined to a single intra-abdominal compartment, which makes comparisons between individual subjects easier and logically suggests that the chances of identifying a regional pressure phenomenon would be highest.

The two primary aims of the current study were to compare the IBP to that immediately outside within the intra-peritoneal pelvis and to establish whether there are any regional variations in IAP between the upper and lower abdominal compartments (upper intra-abdominal pressure, UIAP and lower intra-abdominal pressure, LIAP) following liver transplantation. A secondary endpoint was to examine the effect, if any, of body position on the compartmental pressures.

\section{Methods}

Following approval of the study design by the local Research Ethics and Research \& Development Committees, a total of 20 patients undergoing elective orthotopic transplantation were recruited, all of whom gave informed consent to take part in this study. All patients received cadaveric whole grafts and had not undergone liver transplantation previously. Data were collected during the subjects' stay on a 15-bed dedicated Liver Intensive Care Unit with aspects of post-operative care such as the administration of intra-venous fluids and the use of vaso-active agents, guided by established unit protocol. All subjects were nursed in a $30^{\circ}$ head of bed position to minimise risk of respiratory complications with the exception of short periods of being laid flat in order to measure supine IAP. All were calm and comfortable at the time of measurement (Richmond agitation-sedation scale of 0 ).

For each patient, UIAP and LIAP were measured directly via catheters placed under the left lobe of the transplanted organ and in the pelvis at the time of operation (Minivac Drain, Unomedical, Worcestershire, UK). These catheters were connected, via a fluid column to an electronic pressure transducer with numeric and pressure trace displayed on the ICU monitor (Fukuda Denshi Co., Ltd, Tokyo, Japan). These catheters were used solely for measurement of IAP and not for drainage. Standard closed surgical drains were placed in the usual position to prevent accumulation of body fluids.

The electronic transducers were fixed to the patient by sutures at a point corresponding to the internal position of the catheter tips on the upper and lower abdominal wall. A position that was found to correspond to the zero-reference point as suggested by the WSACS, of the mid-axillary line at the iliac crest when supine. The transducers were flushed and zeroed twice daily and after each patient position change. The measured dead space of the catheter was $<2 \mathrm{ml}$, and thus, a 4-ml flush with normal saline, from a sterile closed system, ensured a continuous column of fluid between the intra-peritoneal catheter tip and the transducer which was maintained between flushes by continuous low volume irrigation. The quality of the pressure waveform was checked hourly by the 'rapid oscillation test [21]', whereby rapid and repeated palpation of the abdominal wall at the level of the intra-peritoneal catheter tip was visible in real time on the ICU monitor's pressure trace (Figure 1).

Compartmental IAP was transduced continuously via this equipment, and the monitoring system recorded paired measurement of UIAP and LIAP at 10-min interval. The catheters were left in place for a maximum of $72 \mathrm{~h}$ or until the point of discharge from the Liver Intensive Care Unit, whichever came sooner. 


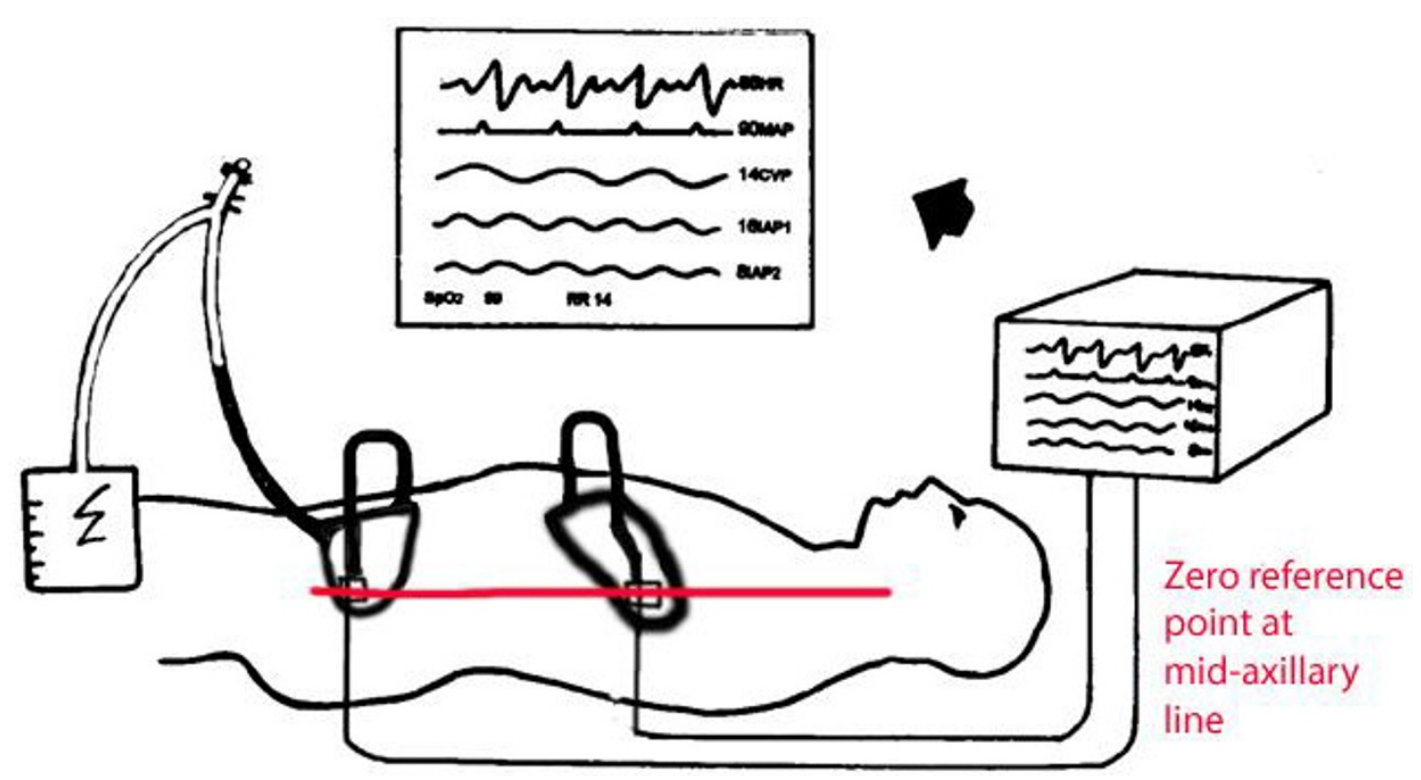

Figure 1 Equipment set-up to transduce LIAP and UIAP along with FoleyManometer for measurement of IBP.

Each patient was re-positioned to lie supine at 6-hour intervals (four times per day) in order to measure the supine compartmental pressures. The transducers were 're-zeroed' following each position change, and the pressure was allowed to equilibrate for $5 \mathrm{~min}$ prior to making each of these recordings.

In addition to the direct pressure measurements, IBP was also recorded at 6-h intervals with the patient both in a $30^{\circ}$ head up and supine positions using a FoleyManometer system (Holtech medical Company, Charlottenlund, Denmark), as shown in Figure 2.

\section{Statistical analysis}

The data were recorded in a Microsoft Excel Spreadsheet (Microsoft, WA, USA) and analysed using SPSS v15 (Chicago, IL, USA) in accordance with the recommendations for data analysis published by the WSACS [29]. Data obtained at 6-hourly intervals (IBP, LIAP and UIAP at supine and $30^{\circ}$ head of bed angles) were compared by means of a Bland and Altman analysis [30]. The coefficient of variance of IAP was defined as the standard deviation of IAP divided by the mean IAP. Percentage error of the measurement was defined as twice the precision divided by the mean IAP. The normality of distribution of the continuous pressure recordings was tested using a Kolmogorov-Smirnov test, and being parametric and normally distributed, means were compared using a paired $t$ test.

Following professional statistical advice and in order to perform both within and between individual comparisons of the difference in compartmental pressures in subjects with differing baseline IAP, the difference between the two compartmental recordings was converted to a percentage of the mean of both compartments (Difference $\div$ $($ mean of UIAP + LIAP $) \times 100)$. This eliminated the effect of the underlying baseline IAP and inter-individual variations. For the same reason, the trend in compartmental pressure over time was expressed as the difference in each subsequent pressure recording over the initial IAP. The differences in compartmental pressures over time were normally distributed and, therefore, compared by linear regression. For the purpose of reporting, a difference of $4 \mathrm{mmHg}$ or greater between the compartments was considered to be clinically significant.

\section{Results}

Comparison of direct and indirect measurement of lower intra-abdominal pressure

There was no clinically relevant difference between the mean measurements made via the pelvic transducer and the foley manometer. The Bland and Altman plot (Figure 3a, b, c) confirmed excellent agreement between the two measures in all body positions, with a calculated bias and precision of -0.06 and 0.6 when supine and 0.006 and 0.5 at $30^{\circ}$. Full details of the two measurements are given in Table 1.

\section{Compartmental pressure measurements}

A total of 169 synchronous measurements of IBP, LIAP and UIAP were made to obtain compartmental pressure with subjects in a supine and $30^{\circ}$ head of bed position at 6-h intervals. In contrast to the excellent agreement between IBP and LIAP, comparisons of both IBP and UIAP, and LIAP and UIAP revealed very poor agreement 


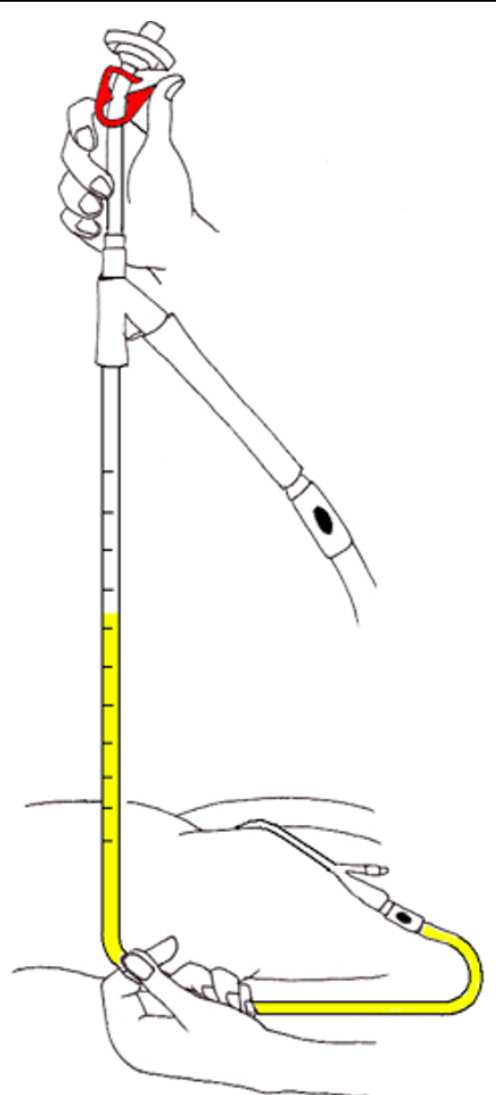

Figure 2 Technique for using FoleyManometer for the measurement of intra-abdominal pressure. IBP marked by arrow.

with a high measured bias, precision and percentage error (Table 1 and Figure 4a, b). Parameters for these comparisons fell well outside the thresholds for agreement stated by the WSACS [29].

The mean UIAP when supine was $11.7 \mathrm{mmHg}$, which was reduced to $9.6 \mathrm{mmHg}$ with $30^{\circ}$ head of bed positioning $(p<0.001)$. Mean LIAP was $9.2 \mathrm{mmHg}$ when supine and increased to $9.6 \mathrm{mmHg}$ with $30^{\circ}$ head of bed $(p<0.001)$.

The increase in UIAP with a move to a supine position was observed in all patients, irrespective of which compartment contained the higher pressure. The observed magnitude of change in mean UIAP was not different between subjects exhibiting a raised IAP $(>12 \mathrm{mmHg}$ ) and those with a normal IAP (2.4 and $1.8 \mathrm{mmHg}$ change, respectively; $p=0.5$ ). Similarly, although there was a suggestion that subjects with higher upper than lower compartmental pressures exhibited a larger change in UIAP when moving to a supine position $(2.4$ and $1.1 \mathrm{mmHg}$ change, respectively), this difference was not statistically significant $(p=0.9)$.

\section{Continuous pressure measurements}

A total of 5,980 automated-paired pressure measurements of direct LIAP and UIAP were recorded with an average of 299 per patient (range 212 to 461). Of the 20 subjects, 12 revealed a higher mean pressure within the UIAP than the LIAP compartment, with the greatest mean pressure difference for an individual being $5.3 \mathrm{mmHg}$.

When analysed as a whole and as sub-groups with either higher UIAP or higher LIAP, the difference between the compartmental pressures was highly statistically significant $(p<0.001, p<0.001$ and $p<0.004$, respectively). The range of differences between compartmental pressures in the two groups also differed with those exhibiting a higher UIAP having a broader range $(0$ to $16 \mathrm{mmHg}$ ) than those with a higher LIAP (0 to 12 $\mathrm{mmHg}$ ). The mean pressures observed in each compartment for the subjects as a whole and for the two subgroups are displayed in Table 2.

The mean difference between the two compartments was similar, whether it was the upper or lower compartment that contained the higher pressure. Expressed as a percentage of the mean of the two compartments, this equated to a clinically significant $23.4 \%$ difference when UIAP was highest, and $23.6 \%$ when LIAP was highest.

Individual analysis of each subject's data confirmed the significant difference $(p<0.001)$ between compartments for all but two patients. In two individuals, the 
(a)

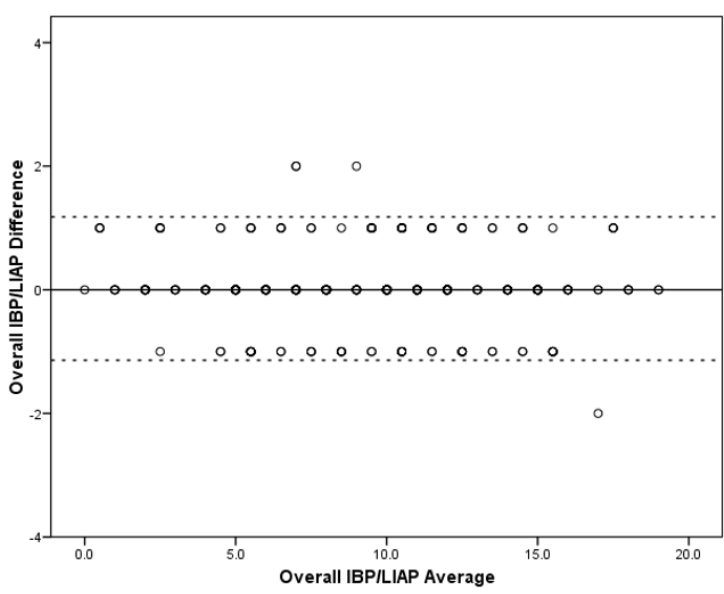

(b)

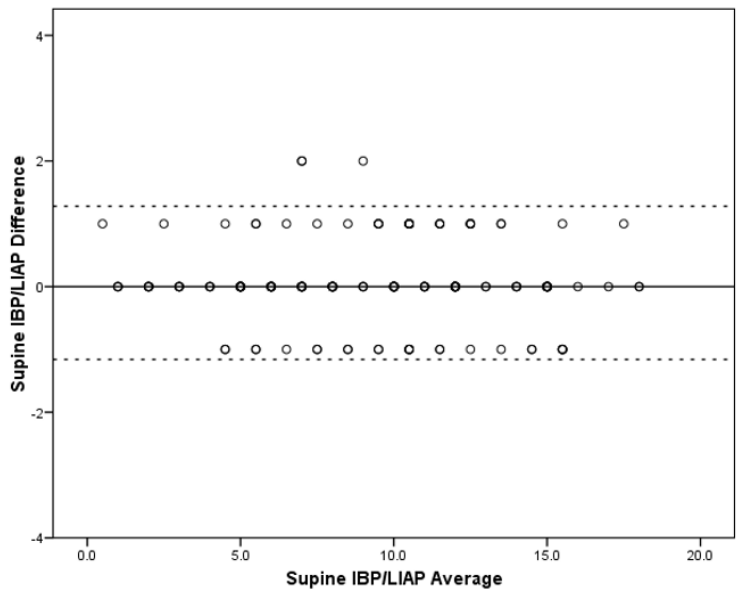

(c)

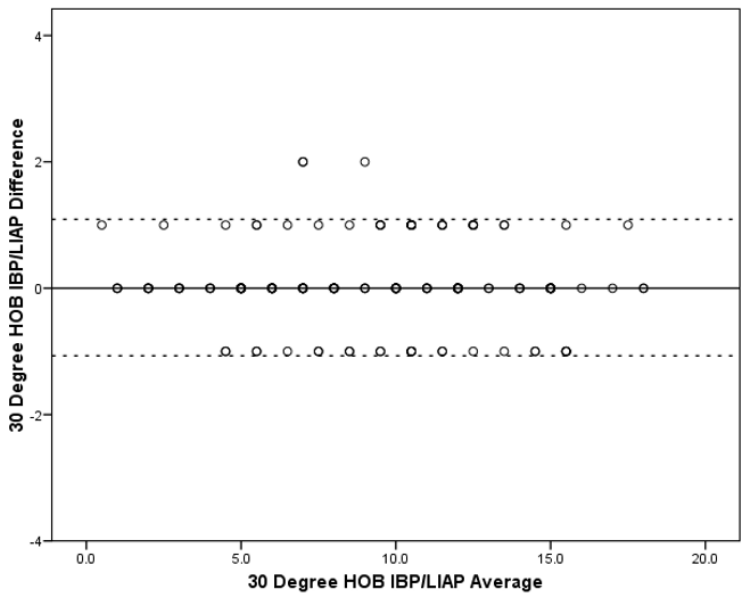

Figure 3 Bland and Altman plots comparing intra-bladder pressure (IBP) and lower intra-abdominal pressure (LIAP). (a) Bland and Altman plot to compare IBP and LIAP with a supine body position and a head of bed position of $30^{\circ}$. (b) Bland and Altman plot to compare IBP and LIAP with a supine body position.(c) Bland and Altman plot to compare IBP and LIAP with a head of bed position of $30^{\circ}$. Lower level of agreement (LLA) and upper level of agreement (ULA) marked by dotted lines. 
Table 1 Comparison of IBP, LIAP and UIAP

\begin{tabular}{ccccccccccccc}
\hline \multicolumn{2}{c}{ Comparisons } & Number & Mean IAP & Range IAP & COVA IAP & $\boldsymbol{r}^{\mathbf{a}}$ & $\boldsymbol{p}$ & Bias & Precision & LLA & ULA & \% Error \\
\hline IBP vs LIAP & All & 338 & 9.43 & 0.0 to 19.0 & 43.6 & 0.99 & $<0.001$ & 0.03 & 0.59 & -1.14 & 1.18 & 13 \\
& Supine & 169 & 9.23 & 0.5 to 18.0 & 43.7 & 0.99 & $<0.001$ & 0.06 & 0.62 & -1.16 & 1.28 & 13 \\
& $30^{\circ} \mathrm{HOB}$ & 169 & 9.63 & 0.0 to 19.0 & 43.6 & 0.99 & $<0.001$ & -0.01 & 0.55 & -1.07 & 1.09 & 11 \\
\multirow{4}{*}{ IBP vs UIAP } & All & 338 & 10.07 & 1.5 to 19.5 & 39.7 & 0.66 & $<0.001$ & -1.25 & 3.63 & -8.36 & 5.86 & 72 \\
& Supine & 169 & 10.49 & 2.5 to 19.5 & 38.9 & 0.70 & $<0.001$ & -2.46 & 3.52 & -9.36 & 4.44 & 67 \\
& $30^{\circ} \mathrm{HOB}$ & 169 & 9.65 & 1.5 to 18.5 & 39.9 & 0.68 & $<0.001$ & -0.05 & 3.34 & -6.60 & 6.5 & 69 \\
\multirow{4}{*}{ LIAP vs UIAP } & All & 338 & 10.06 & 1.5 to 19.5 & 39.8 & 0.66 & $<0.001$ & -1.28 & 3.63 & -7.31 & 4.75 & 72 \\
& Supine & 169 & 10.46 & 2.5 to 19.5 & 39.3 & 0.70 & $<0.001$ & -2.51 & 3.47 & -9.31 & 4.29 & 66 \\
& $30^{\circ} \mathrm{HOB}$ & 169 & 9.66 & 1.5 to 18.0 & 40.1 & 0.68 & $<0.001$ & -0.05 & 3.36 & -6.64 & 6.54 & 70 \\
\hline
\end{tabular}

The patient positioned supine and in a $30^{\circ}$ head of bed angle. IBP, intra-bladder pressure; LIAP, lower intra-abdominal pressure; UIAP, upper intra-abdominal pressure; $\mathrm{HOB}$, head of bed, IAP, intra-abdominal pressure; COVA; coefficient of variance; LLA, Lower level of agreement; ULA, Upper level of agreement. ${ }^{a} r=$ Pearson product-moment correlation coefficient.

compartmental pressures did not differ significantly ( $p=$ 0.349 and 0.122 , respectively); however, the mean IAPs for both patients and in both compartments fell within normal safe limits (7.1 and $7.3 \mathrm{mmHg}$, and 11.4 and $12.0 \mathrm{mmHg}$, respectively).

Nine subjects displayed a continuous pressure $>12$ $\mathrm{mmHg}$ in one or other compartment for greater than 1 h. Of these, five had higher mean UIAP, and four had higher LIAP. There was no difference between the mean difference in compartmental pressures in subjects with a sustained pressure of $>12 \mathrm{mmHg}$ compared to those without ( 2.3 and $2.1 \mathrm{mmHg}$, respectively; $p=0.772$ ).

In the higher UIAP group, a clinically significant difference of $4 \mathrm{mmHg}$ or more between compartmental pressures was observed during an average of $23 \%$ of the study period. This proportion was higher in the higher LIAP group at $37 \%$ of the study duration; however, these differences were not statistically significant ( $p=$ 0.666). The direction of change in compartmental IAP over time correlated positively such that an overall upward trend in UIAP was accompanied by an upward trend in LIAP $\left(r^{2}=0.582, p<0.001, n=5,960\right)$.

\section{Discussion}

The recognition and treatment of IAH and the abdominal compartment syndrome (ACS) are clearly reliant on an accurate and reliable system for the measurement of IAP. The technique for IBP measurement has undergone much refinement over the last decade [21] and has now been presented, by an international panel of experts, as the gold standard for intra-abdominal pressure measurement [17]. In addition to the effects of gravity and sheer stress [31], the value of bladder pressure relies on two key assumptions which have been widely accepted without direct evidence of their validity.

The first assumption is that the bladder wall will act as a passive diaphragm to the transmission of pressure, and therefore, the pressure measured within the urinary bladder will accurately reflect the pressure immediately outside within the peritoneal cavity. Several studies, in both animal and human models, have shown good agreement between directly and indirectly measured intraabdominal pressure [22,23,32,33]. All of these studies, however, have measured direct IAP at a site distant to the urinary bladder and followed artificial elevation of IAP by means of either saline or gas insufflation, or by insertion of a mechanical prosthesis. Our data is the first to directly compare the pressure measured at the intravesical and intra-peritoneal sides of the bladder wall and confirms that the pressure measured within the urinary bladder demonstrates excellent agreement with the pressure to be measured within the pelvic peritoneal cavity.

The second assumption relates to the mechanical properties of the peritoneal contents. It has been suggested that the abdominal contents are primarily fluid in composition and, therefore, that pressure transmission can be expected to follow Pascal's law such that measurement of the IAP at any point will reflect the pressure contained within the entire abdominal cavity [21]. In reality, however, the abdominal contents remain a heterogeneous mix of solid, liquid and gaseous components with the exact composition influenced by several disease processes such as paralytic ileus, visceral oedema, or the presence of ascites. Pressure transmission characteristics are, therefore, likely to be rather more complex.

\section{Regional IAP}

The implications of a regional ACS are profound with the gold-standard technique for pressure measurement occurring at the lowest point in the abdominal cavity, whilst the organs that have been shown to be most susceptible to raised IAP all lie in the upper abdomen. Separate studies have all clearly shown the deleterious effects of raised IAP on the splanchnic circulation $[11-13,34,35]$, cardiac $[8,36]$, respiratory $[9,37,38]$, renal $[5,32,39]$ and neurological $[40,41]$ functions in both human and animal models. 
(a)

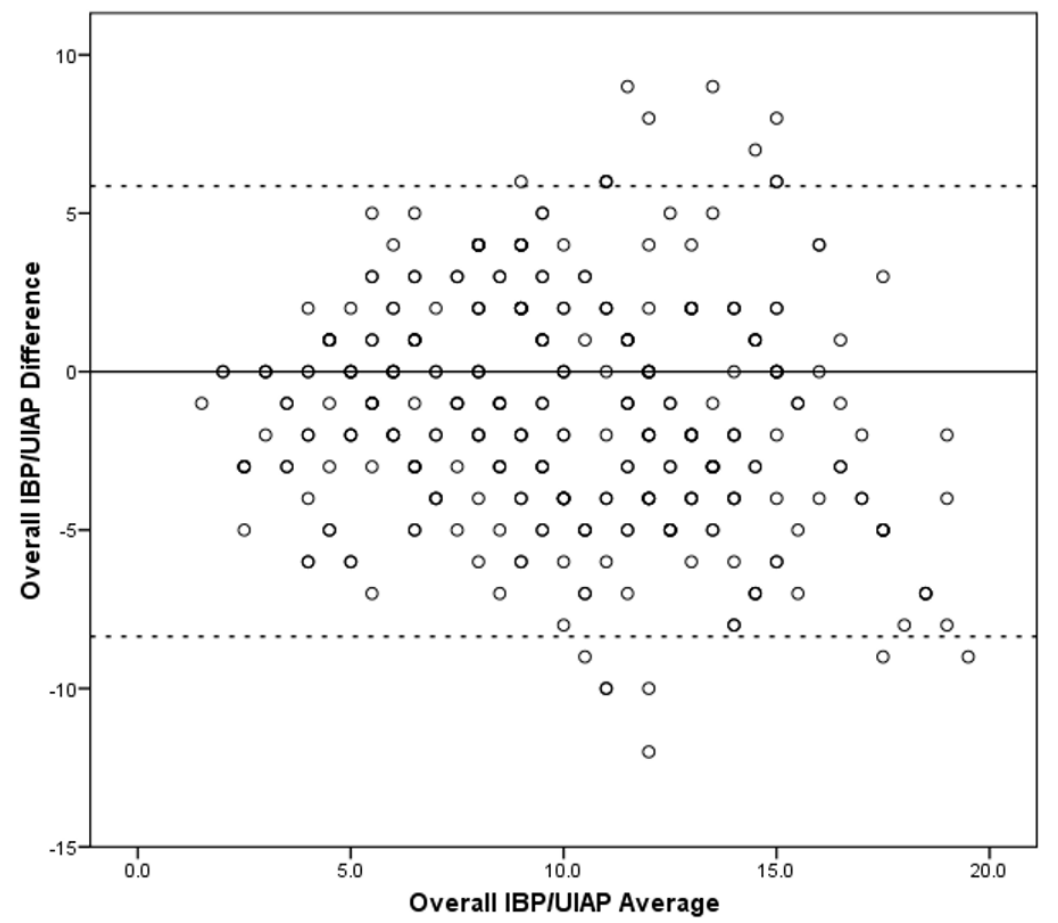

(b)

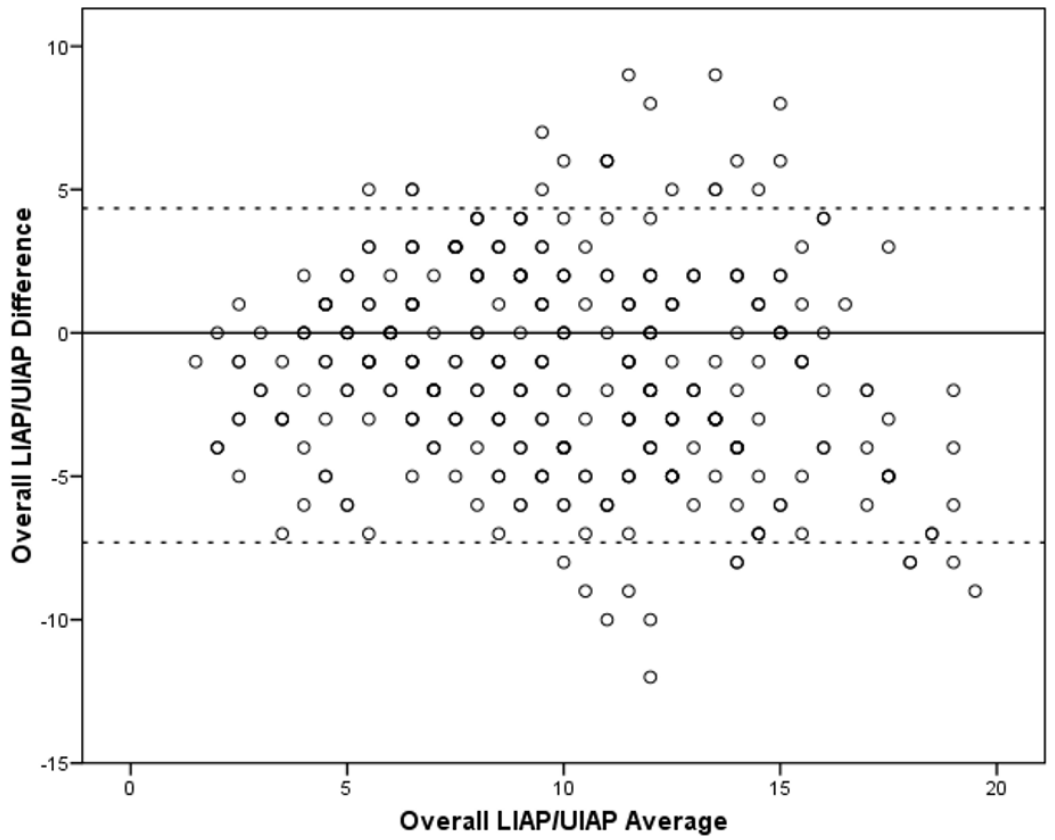

Figure 4 Intra-bladder pressure (IBP) and upper intra-abdominal pressure (UIAP), and lower intra-abdominal pressure (LIAP) and UIAP (a) Bland and Altman plot to compare IBP and UIAP with a supine body position and a head of bed position of $30^{\circ}$. (b) Bland and Altman plot to compare LIAP and UIAP with a supine body position and a head of bed position of $30^{\circ}$. LLA and ULA marked by dotted lines.

The possibility of a regional variation between the upper and lower IAP was identified, but not explored in detail in 1994 [22]. In this study, IGP was measured in nine patients undergoing laparoscopic cholecystectomy at a variety of different insufflation pressures. The study was designed to validate the measurement of IGP 
Table 2 Mean continuous pressures observed in each compartment, split according to highest average compartment pressure

\begin{tabular}{|c|c|c|c|c|}
\hline \multirow[t]{2}{*}{ Subject group } & \multicolumn{2}{|c|}{$\begin{array}{c}\text { Mean } \\
\underset{(\mathrm{mmHg}, \mathrm{SD})}{\text { compartmental IAP }}\end{array}$} & \multirow[t]{2}{*}{ Mean difference between compartments (SD) } & \multirow[t]{2}{*}{ Mean percentage difference between compartments $\mathrm{s}^{\mathrm{a}}$} \\
\hline & UIAP & LIAP & & \\
\hline Higher & 10.5 & 8.3 & 2.2 & $23.4 \%$ \\
\hline UIAP & (4.6) & $(4.5)$ & $(2.4)$ & \\
\hline Higher & 8.6 & 10.9 & 2.3 & $23.6 \%$ \\
\hline LIAP & (3.8) & $(5.6)$ & (3.2) & \\
\hline \multirow[t]{2}{*}{ Overall } & 9.7 & 9.5 & 0.3 & $3.1 \%$ \\
\hline & $(4.2)$ & (4.6) & $(4.1)$ & \\
\hline
\end{tabular}

UIAP, upper intra-abdominal pressure; LIAP, lower intra-abdominal pressure; SD, Standard Deviation. ${ }^{a}$ Mean percentage difference between compartments = mean difference between compartments/(mean UIAP + mean LIAP/2) $\times 100$.

against the pneumoperitoneum but also showed that IGP could also be up to $4 \mathrm{mmHg}$ higher or $3 \mathrm{mmHg}$ lower than the measured IBP. A further small study has identified differences in gastric and bladder pressure in two patients within a general ICU population [42] and suggested that such a variation could provide clues as to any underlying pathophysiological process.

Our study is the largest to compare the two compartmental pressures within a clinical setting, without artificial manipulation of IAP. In keeping with the above study, we showed a significant difference between compartmental pressures but with a much broader and more clinically significant range of variation of up to 16 $\mathrm{mmHg}$ and a mean difference between the compartments of around $20 \%$ which equates to a maximal intercompartmental mean difference of $5.3 \mathrm{mmHg}$.

Clearly, such a magnitude of variation, coupled with the observation that compartmental pressures were seen to vary by $4 \mathrm{mmHg}$ or more for an average of $23 \%$ of the time, means that relying on the measurement of one compartmental pressure only may lead to a significantly elevated pressure in the other compartment being missed. The positive relationship that we have demonstrated between compartmental pressures should mandate separate measurement of UIAP in patients in whom the IBP is adopting an upward trend.

It was interesting to observe that the range of variation in inter-compartmental pressure was greater in those patients concealing a higher UIAP, and this may be related to the previous data which suggest that upper abdominal incisions result in measurable changes to abdominal wall contractile properties which may contribute to the generation of a locally raised IAP [43].

\section{Body position and regional IAP}

Previous clinical studies have considered the influence of patient positioning on IAP. In the largest [44], a multicentre study of 132 ventilated patients, the mean difference between supine and $30^{\circ} \mathrm{IBP}$ was $3.7 \mathrm{mmHg}$ with a range of 3.4 to $4.0 \mathrm{mmHg}$. The largest reported difference in positional pressures was seen in a study of 37 patients at a range of bed positions between 0 and $45^{\circ}$ [27]. It was found that IBP increased with head-up tilt with a mean increase of $5 \mathrm{mmHg}$ at $30^{\circ}$, and $7.4 \mathrm{mmHg}$ at $45^{\circ}$.

Our data have also demonstrated a statistically significant increase in the IBP with head-up positioning to $30^{\circ}$. This was, however, a far smaller increase of just $0.43 \mathrm{mmHg}$ rather than the $5 \mathrm{mmHg}$ seen in the above study. This would lend support to the theory that LIAP will increase as the result of a more upright posture [33]. The most likely explanation for this is that an erect posture leads to an increase in the hydrostatic weight exerted by the abdominal organs and body habitus pressing downwards on the bladder much in the same manner as increasing the height of a standing column of fluid would increase the measurable pressure at the bottom of the column.

A more interesting observation in our own data, however, is the fact that despite accurate re-zeroing of a patient mounted transducer UIAP was significantly increased in the supine position compared to a $30^{\circ}$ head-up tilt. The reason for this observation remains unclear but may be related to the re-positioning of the more mobile hollow abdominal viscera along with both their fluid contents and any free intra-peritoneal fluid with a more upright posture. This observation would suggest that a simple change in posture could provide a clinically significant improvement in the UIAP, which in turn, may improve hepatic, renal and splanchnic blood flow. Such positive effects on organ perfusion would need to be demonstrated by further specific studies; however, it does raise the possibility that a head-up position may be advantageous for reasons other than simple ventilatory mechanics. It is also particularly encouraging to note that a larger reduction in UIAP can be expected in those patients with a higher upper, rather than lower, baseline intra-abdominal pressure. The lack 
of collection of other body anthropomorphic data to further examine these two groups is accepted to be an unfortunate limitation of the study.

\section{Clinical application}

The fact that it was impossible to predict which of the two compartments would conceal the higher pressure suggests that, for this subgroup of patients, dual compartmental pressure monitoring may be required based upon the clinical condition of the patient. It remains unclear, however, whether the observed variation in inter-compartmental pressure is specific to the procedure of liver transplantation, or whether the findings could be generalised to all upper abdominal surgery, local inflammatory conditions such as severe acute pancreatitis, or indeed the measurement of IAP in general. It is also a shortcoming that various anthropomorphic data and details of illness severity scores were not collected, as these have been shown to impact on baseline IAP.

Further study with a larger sample size will be required to elucidate the relationship between the location of the higher compartmental pressure, the magnitude of variation in compartmental pressure and the duration for which there is a significant difference between compartments with clinical outcome. Such a study, with higher numbers, may be facilitated by the recent introduction of a commercially available noninvasive device for the measurement of IGP (CiMON, Pulsion Medical Systems, Munich, Germany). It would also be extremely interesting to measure the retroperitoneal compartmental pressure within the upper abdomen which very much contains the 'anatomical terminus' for the arrival and departure of the abdominal blood supply, as well as the kidneys themselves.

\section{Conclusion}

It remains to be seen and further research is certainly required to discover whether the observed effects are specific to patients undergoing liver transplantation and to define any effects on clinical outcome. The current data do, however, demonstrate a significant variation in regional IAP within the study group. It may be well that we need to consider regional IAP in more detail and consider the different abdominal compartments, including the retroperitoneum, as more distinct entities, and patient positioning may prove a useful utility for optimising compartmental pressures and perfusion.

\section{Consent}

Written informed consent was obtained from the patient for publication of this case report and accompanying images. A copy of the written consent is available for review by the Editor-in-Chief of this journal.

\section{Abbreviations}

ACS: abdominal compartment syndrome; $\mid \mathrm{AH}$ : intra-abdominal hypertension; IAP: intra-abdominal pressure; IBP: intra-bladder pressure; ICU: intensive care unit; IGP: intra-gastric pressure; LIAP: lower intra-abdominal pressure; UIAP: upper intra-abdominal pressure; WSACS: World Society on Abdominal Compartment Syndrome.

\section{Acknowledgements}

This article has been published as part of Annals of Intensive Care Volume 2 Supplement 1, 2012: Diagnosis and management of intra-abdominal hypertension and abdominal compartment syndrome. The full contents of the supplement are available online at http://www.annalsofintensivecare. com/supplements/2/S1.

Figure 2 is reproduced with the kind permission of Mr. Bo Holte, Holtech, Charlottenlund, Denmark. The authors wish to thank Pulsion Medical Systems who have sponsored the processing fees for this article.

\section{Authors' contributions}

$A B C$ conceived of the idea, designed the study, arranged ethical approval, conducted the study, collected the data, analysed the data and wrote the manuscript. JAW and MJB reviewed the study design, assisted with analysis and reviewed the manuscript. WJ, PS, AAP, ES, WB, GA, PM, MR and NDH assisted in the insertion and the day-to-day care of the experimental pressure catheters.

\section{Authors' information}

$A B C$ is now a hepatopancreatobiliary (HPB) surgeon at the Basingstoke Hepatobiliary Unit, UK. WJ, PS, AAP, MR and NDH are HPB and liver transplant surgeons at King's College Hospital, UK. JAW, ES, WB and GA are liver intensivists at King's College Hospital, UK. MJB is an HPB surgeon at Derriford Hospital, UK but undertook this work whilst a HPB and transplant surgeon at Kings College Hospital.

\section{Competing interests}

Dr Julia Wendon is a member of the medical advisory board of Pulsion Medical Systems, who have sponsored the processing fees of this submission. The authors declare that they have no other conflicts of interests.

Published: 5 July 2012

\section{References}

1. Malbrain ML, Chiumello D, Pelosi P, Bihari D, Innes R, Ranieri VM, Del Turco M, Wilmer A, Brienza N, Malcangi V, Cohen J, Japiassu A, De Keulenaer BL, Daelemans R, Jacquet L, Laterre PF, Frank G, de Souza P, Cesana B, Gattinoni L: Incidence and prognosis of intraabdominal hypertension in a mixed population of critically ill patients: a multiplecenter epidemiological study. Crit Care Med 2005, 33:315-322.

2. Malbrain ML, Chiumello D, Pelosi P, Wilmer A, Brienza N, Malcangi V, Bihari D, Innes R, Cohen J, Singer P, Japiassu A, Kurtop E, De Keulenaer BL, Daelemans R, Del Turco M, Cosimini P, Ranieri M, Jacquet L, Laterre PF, Gattinoni L: Prevalence of intra-abdominal hypertension in critically ill patients: a multicentre epidemiological study. Intensive Care Med 2004, 30:822-829.

3. Malbrain ML, Deeren D, De Potter TJ: Intra-abdominal hypertension in the critically ill: it is time to pay attention. Curr Opin Crit Care 2005, 11:156-171.

4. Balogh Z, De Waele JJ, Kirkpatrick A, Cheatham M, D'Amours S, Malbrain M: Intra-abdominal pressure measurement and abdominal compartment syndrome: the opinion of the World Society of the Abdominal Compartment Syndrome. Crit Care Med 2007, 35:677-678, author reply 678-679.

5. Biancofiore G, Bindi ML, Romanelli AM, Bisa M, Boldrini A, Consani G, Filipponi F, Mosca F: Postoperative intra-abdominal pressure and renal function after liver transplantation. Arch Surg 2003, 138:703-706.

6. Bloomfield GL, Blocher CR, Fakhry IF, Sica DA, Sugerman HJ: Elevated intraabdominal pressure increases plasma renin activity and aldosterone levels. J Trauma 1997, 42:997-1004, discussion 1004-1005.

7. Bongard F, Pianim N, Dubecz S, Klein SR: Adverse consequences of increased intra-abdominal pressure on bowel tissue oxygen. J Trauma 1995, 39:519-524, discussion 524-515. 
8. Cheatham ML, Malbrain ML: Cardiovascular implications of abdominal compartment syndrome. Acta Clin Belg Suppl 2007, 1:98-112.

9. D'Angelo E, Pecchiari M, Acocella F, Monaco A, Bellemare F: Effects of abdominal distension on breathing pattern and respiratory mechanics in rabbits. Respir Physiol Neurobiol 2002, 130:293-304.

10. De laet I, Malbrain ML, Jadoul JL, Rogiers P, Sugrue M: Renal implications of increased intra-abdominal pressure: are the kidneys the canary for abdominal hypertension? Acta Clin Belg Suppl 2007, 1:119-130.

11. Diebel LN, Dulchavsky SA, Wilson RF: Effect of increased intra-abdominal pressure on mesenteric arterial and intestinal mucosal blood flow. J Trauma 1992, 33:45-48, discussion 48-49.

12. Diebel LN, Wilson RF, Dulchavsky SA, Saxe J: Effect of increased intraabdominal pressure on hepatic arterial, portal venous, and hepatic microcirculatory blood flow. J Trauma 1992, 33:279-282, discussion 282273.

13. Eleftheriadis $\mathrm{E}$, Kotzampassi $\mathrm{K}$ : Hepatic microcirculation after continuous 7-day elevated intra-abdominal pressure in cirrhotic rats. Hepatol Res 2005, 32:96-100.

14. Ivatury RR, Diebel L, Porter JM, Simon RJ: Intra-abdominal hypertension and the abdominal compartment syndrome. Surg Clin North Am 1997, 77:783-800.

15. Malbrain ML, Cheatham ML, Kirkpatrick A, Sugrue M, De Waele J, Ivatury R Abdominal compartment syndrome: it's time to pay attention! Intensive Care Med 2006, 32:1912-1914

16. Malbrain ML, Cheatham ML, Kirkpatrick A, Sugrue M, Parr M, De Waele J, Balogh Z, Leppaniemi A, Olvera C, Ivatury R, D'Amours S, Wendon J, Hillman K, Johansson K, Kolkman K, Wilmer A: Results from the International Conference of Experts on Intra-abdominal Hypertension and Abdominal Compartment Syndrome. I. Definitions. Intensive Care Med 2006, 32:1722-1732

17. Cheatham ML, Malbrain ML, Kirkpatrick A, Sugrue M, Parr M, De Waele J, Balogh Z, Leppaniemi A, Olvera C, Ivatury R, D'Amours S, Wendon J, Hillman K, Johansson K, Kolkman K, Wilmer A: Results from the International Conference of Experts on Intra-abdominal Hypertension and Abdominal Compartment Syndrome. II. Recommendations. Intensive Care Med 2007.

18. Malbrain ML, De laet I, Van Regenmortel N, Schoonheydt K, Dits H: Can the abdominal perimeter be used as an accurate estimation of intraabdominal pressure? Crit Care Med 2009, 37:316-319

19. Kirkpatrick AW, Brenneman FD, McLean RF, Rapanos T, Boulanger BR: Is clinical examination an accurate indicator of raised intra-abdominal pressure in critically injured patients? Can I Surg 2000, 43:207-211.

20. Sugrue M, Bauman A, Jones F, Bishop G, Flabouris A, Parr M, Stewart A, Hillman K, Deane SA: Clinical examination is an inaccurate predictor of intraabdominal pressure. World J Surg 2002, 26:1428-1431.

21. Malbrain ML: Different techniques to measure intra-abdominal pressure (IAP): time for a critical re-appraisal. Intensive Care Med 2004, 30:357-371.

22. Sugrue M, Buist MD, Lee A, Sanchez DJ, Hillman KM: Intra-abdominal pressure measurement using a modified nasogastric tube: description and validation of a new technique. Intensive Care Med 1994, 20:588-590.

23. Risin E, Kessel B, Ashkenazi I, Lieberman N, Alfici R: A new technique of direct intra-abdominal pressure measurement: a preliminary study. Am J Surg 2006, 191:235-237.

24. Schachtrupp A, Henzler D, Orfao S, Schaefer W, Schwab R, Becker P, Schumpelick V: Evaluation of a modified piezoresistive technique and a water-capsule technique for direct and continuous measurement of intra-abdominal pressure in a porcine model. Crit Care Med 2006, 34:745-750.

25. Risin E, Kessel B, Lieberman N, Schmilovich M, Ashkenazi I, Alfici R: New technique of direct intra-abdominal pressure measurement. Asian J Surg 2006, 29:247-250.

26. Malbrain ML, Wilmer A: The polycompartment syndrome: towards an understanding of the interactions between different compartments! Intensive Care Med 2007, 33:1869-1872.

27. McBeth PB, Zygun DA, Widder S, Cheatham M, Zengerink I, Glowa J, Kirkpatrick AW: Effect of patient positioning on intra-abdominal pressure monitoring. Am J Surg 2007, 193:644-647, discussion 647.

28. Biancofiore G, Bindi ML, Romanelli AM, Boldrini A, Consani G, Bisa M, Filipponi F, Vagelli A, Mosca F: Intra-abdominal pressure monitoring in liver transplant recipients: a prospective study. Intensive Care Med 2003, 29:30-36.
29. De Waele JJ, Cheatham ML, Malbrain ML, Kirkpatrick AW, Sugrue M, Balogh Z, Ivatury R, De Keulenaer B, Kimball EJ: Recommendations for research from the International Conference of Experts on Intraabdominal Hypertension and Abdominal Compartment Syndrome. Acta Clin Belg 2009, 64:203-209.

30. Bland JM, Altman DG: Statistical methods for assessing agreement between two methods of clinical measurement. Lancet 1986, 1:307-310.

31. De Keulenaer BL, De Waele JJ, Powell B, Malbrain ML: What is normal intra-abdominal pressure and how is it affected by positioning, body mass and positive end-expiratory pressure? Intensive Care Med 2009, 35:969-976.

32. Kirkpatrick AW, Colistro R, Laupland KB, Fox DL, Konkin DE, Kock V, Mayo JR, Nicolaou S: Renal arterial resistive index response to intraabdominal hypertension in a porcine model. Crit Care Med 2007, 35:207-213.

33. Shafik A, El-Sharkawy A, Sharaf WM: Direct measurement of intraabdominal pressure in various conditions. Eur J Surg 1997, 163:883-887.

34. Diebel LN, Dulchavsky SA, Brown WJ: Splanchnic ischemia and bacterial translocation in the abdominal compartment syndrome. J Trauma 1997, 43:852-855.

35. Sugrue $M$, Jones F, Lee $A$, Buist MD, Deane $S$, Bauman $A$, Hillman $K$. Intraabdominal pressure and gastric intramucosal $\mathrm{pH}$ : is there an association? World J Surg 1996, 20:988-991.

36. Cullen DJ, Coyle JP, Teplick R, Long MC: Cardiovascular, pulmonary, and renal effects of massively increased intra-abdominal pressure in critically ill patients. Crit Care Med 1989, 17:118-121.

37. Oikkonen $\mathrm{M}$, Tallgren $\mathrm{M}$ : Changes in respiratory compliance at laparoscopy: measurements using side stream spirometry. Can J Anaesth 1995, 42:495-497.

38. Pelosi $\mathrm{P}$, Quintel $\mathrm{M}$, Malbrain ML: Effect of intra-abdominal pressure on respiratory mechanics. Acta Clin Belg Suppl 2007, 1:78-88.

39. Doty JM, Saggi BH, Blocher CR, Fakhry I, Gehr T, Sica D, Sugerman HJ: Effects of increased renal parenchymal pressure on renal function. $J$ Trauma 2000, 48:874-877.

40. De laet I, Citerio G, Malbrain ML: The influence of intraabdominal hypertension on the central nervous system: current insights and clinical recommendations, is it all in the head? Acta Clin Belg Suppl 2007, 1:89-97.

41. Deeren DH, Dits H, Malbrain ML: Correlation between intra-abdominal and intracranial pressure in nontraumatic brain injury. Intensive Care Med 2005, 31:1577-1581.

42. Malbrain ML, De Laet IE, Willems A, Van Regenmortel N, Schoonheydt K, Dits H: Localised abdominal compartment syndrome: bladder-overgastric pressure ratio (B/G ratio) as a clue to diagnosis. Acta Clin Belg 2010, 65:98-106.

43. Duggan JE, Drummond GB: Abdominal muscle activity and intraabdominal pressure after upper abdominal surgery. Anesth Analg 1989, 69:598-603.

44. Cheatham ML, De Waele JJ, De Laet I, De Keulenaer B, Widder S, Kirkpatrick AW, Cresswell AB, Malbrain M, Bodnar Z, Mejia-Mantilla JH, Reis R, Parr M, Schulze R, Puig S, World Society of the Abdominal Compartment Syndrome (WSACS) Clinical Trials Working Group: The impact of body position on intra-abdominal pressure measurement: a multicenter analysis. Crit Care Med 2009, 37:2187-2190.

doi:10.1186/2110-5820-2-S1-S12

Cite this article as: Cresswell et al:: The effect of body position on compartmental intra-abdominal pressure following liver transplantation. Annals of Intensive Care 2012 2(Suppl 1):S12. 